Journal of Teacher Education for Sustainability, vol. 12, no. 2, pp. 129-141

\title{
WASHBACK EFFECTS OF HANDOUTS ON THE TEACHING AND LEARNING PROCESS IN HIGHER EDUCATION INSTITUTIONS IN ETHIOPIA: ADAMA UNIVERSITY IN FOCUS
}

\author{
Robsan Margo Egne \\ University of Oslo, Norway
}

\begin{abstract}
The present study investigates the washback effects of handouts on the teaching and learning process in the higher education institutions of Ethiopia, particularly in Adama University. A descriptive survey and analytical research methods were employed in the present study. A questionnaire, an interview, a document and content analysis were employed to collect data. The data was analysed using quantitative and qualitative approaches. The data gathered through the close-ended items of the questionnaire was analysed quantitatively using the chi-square statistic, whereas the data collected via some interview guides and some items of the questionnaire was analysed using the percentage. Besides, the qualitative data gathered via the open-ended items of the questionnaire, some items of the interview were analysed qualitatively. The research results reveal that the way handouts are being prepared and used in higher education institutions of Ethiopia does not encourage active and independent learning. Some recommendations which are deemed crucial for alleviating the problem are suggested.
\end{abstract}

Key words: handout, washback effect, teaching and learning process, higher education institution

\section{Introduction}

Education is a fundamental human right which is the key to sustainable development, peace and stability among countries. Besides, education is an indispensable means for effective participation in society and economies of the twenty-first century which is influenced by globalisation (King, 1995). As such, it has a direct and positive effect on earnings, farm productivity and human fertility, as well as an intergenerational effect on children's health and nutrition. Over the past decades, the world has made a remarkable progress towards expanding access to education, and a striking grand achievement has been registered regarding school age population (King \& Hill, 1993; Raudenbush \& Willms, 1991).

For education to play these decisive roles, according to Lockheed and Verspoor (1991), it should meet quality standard in terms of inputs (facilities, qualified teachers, 
parents and community support), processes (effective leadership, monitoring and evaluation, accountability, community participation, effective teaching-learning and student assessment) and outputs (high student learning, societal and individual returns). Though quality in education is relative and not easy to define and measure. As suggested by some scholars (Cook \& Cook, 1998; Farrell, 1989; Fuller, 1986), the quality of education largely depends on the teaching-learning process.

An assumption that higher education can play a great role in both raising awareness among students about sustainable development and giving them the skills to put it into practice is unquestionable. Concerning this argument, Marginson (2008) argues that research is seen as central to the future of nations. The positive impacts of higher learning institutions on the economic development and poverty reduction, particularly in developing countries like Sub-Saharan Africa, are underscored. In this regard, Kofi Annan, as cited in Bloom, Canning and Chan (2006) states that the university must become a primary tool for Africa's development in the new century. Universities can help develop African expertise; they can enhance the analysis of African problems; strengthen domestic institutions; serve as a model environment for the practices of good governance, conflict resolution and respect for human rights, and enable African academics to play an active part in the global community of scholars.

Despite this fact, enrolment rates in higher education in Sub-Saharan Africa are the lowest in the world. Although the gross enrolment ratio has increased in the past 40 years, it is still only 5 percent. The region's progress has been dwarfed by rapid gains in other regions. The growth in enrolment rate has been slow in Sub-Saharan Africa, and the absolute gap by which it lags behind other regions has increased rapidly. The region's present enrolment ratio is in the same range as that of other developing regions 40 years ago (ibid, 2006).

Cognizant of the decisive role education plays to speed up the overall socio-economic progress of the country, the government of Ethiopia has given a high priority to education in its strategy of capacity building and economic development. Since the issuance of the Education and Training Policy (1994), the Ethiopian Ministry of Education has produced a document entitled Higher Education System Overhaul (HESO) that outlines a reform for its tertiary education. Similar to the situation in other African countries, the reform's objectives are to ensure equity, access, accountability, relevance and responsiveness to the demands of the Ethiopian people (Ashcroft, 2004; Wondimu, 2004; Kassaye, 2005; Margo, 2006; Semela, 2006). In sum, the reform process emphasises the perspective of poverty reduction and bringing about sustainable development.

However, unless the graduates of these higher learning institutions have the necessary knowledge, skills and attitude that the present world demands, it is difficult to realise the aspired development. In this regard, among other things, the inputs being used in the teaching-learning process have far reaching impacts. Regarding this point, Rajput (1996) argues that the resources for learning that a teacher and his/her students use can influence the effectiveness of the instructional programme. The creative use of such materials will increase the probability that the students learn more, retain better and improve their performance. One of these inputs is the handout being prepared and used by teachers in the teaching and learning process, particularly in higher education establishments. 


\section{Theoretical framework and basic questions of the study}

A handout is an elusive concept. This is because different scholars define it in different ways. For certain people, a handout is something given for free or without compensation. In this sense, a handout is related to a charitable gift. For some other people, a handout is a resource which supports the teaching and learning process. A handout is considered to be a paper-based resource that supports the teaching and learning process which can free students from excessive note taking or supplement information not easily available elsewhere. Ideally, it should aid learning and may increase attention and motivation and help students to follow the development of an idea or argument.

Similarly, Ellington and Race (1993) describe handouts as types of information providing materials that are given to students or trainees, usually in connection with the lesson to be taught or a programme of some sort. They include sets of notes, tables, diagrams, maps and illustrative or extension materials.

Moreover, according to Wallace (1999), a handout helps students remember a presentation long after it is over, presents information visually, which meets the needs of visual learners, allows students to concentrate on presentation rather than trying to write down everything the teacher says, provides students with a guide to help them with future research and gives the teacher something to refer to when planning future sessions.

Here, it is clear that a handout particularly addresses the interests of visual learners. Tal (2005) states that transformative pedagogies require an approach that goes beyond traditional formats and addresses the various educational needs of the learners at the cognitive, psychomotor and affective levels.

Higher education establishments should implement pedagogical transformation that promotes transformative and interdisciplinary learning. This effort, among other things, helps the learners to engage in critical thinking, reflection, dialogue, problem-solving and knowledge production instead of simply consuming the ready-made knowledge.

The need for handouts to facilitate the teaching and learning process, especially in higher education establishments in developing countries like Ethiopia where there is an acute shortage of references, is unquestionable. But the way the handouts are being prepared and used should encourage students to become voracious readers.

In line with the importance of practicing active learning in the teaching and learning process, according to the Education and Training Policy of Ethiopia (1994), the development of problem-solving capacity in the content of education, curriculum structure and approach, focusing on the acquisition of scientific knowledge and practicum is of utter importance. This implies that the policy is in favour of the constructivism position that argues that humans generate knowledge and meaning from an interaction between their experiences and their ideas.

However, some studies (Serbessa, 2006; Margo, 2005; Margo, 2002) suggest that there is tension between what is stated in the education policy and what is being practised in the actual educational setting of Ethiopia in terms of the practices of active learning. In other words, though the policy emphasises the student-centred approach, the actual practice is still dominated by the teacher-centred approach where students become passive recipients. 
This situation is a "one-size-fits-all" approach to teaching and fails to take the diversity of students and their needs and interests into account. Learning theories show that people normally learn in a quite different modalities, visual, auditory, kinaesthetic (Tessema, 2006). This, in turn, implies that we should emphasise the application of multiple approaches to cater for the diverse learning styles of the students. Regarding this point, McLaren (1989) claims that schools are cultural arenas where a heterogeneity of ideological and social forms often collide in an incessant struggle for dominance.

Here, the researcher argues that one element which makes the traditional teachercentred approach to be sustained in the education system of Ethiopia is the use of handouts, which encourage too much passivity in the students. Hence, there is a need for conducting a research and rectify the mismatch between the intended purpose of using handouts and their limiting side effects on students' learning in the target university. Accordingly, the present research attempts to answer the following questions:

- How do Adama University teachers prepare their handouts? Are there any guidelines in the university helpful for preparing activity-based handouts?

- Do Adama University teachers know the general principles to be followed in preparing activity-oriented handouts?

- Do the teachers know how to use handouts effectively?

- To what extent do the teachers encourage alternatives to handouts such as internet, website, worksheets, references, module guide, and the likes?

\section{Research design and methodology}

In the present research, a handout refers to the sheets of paper that university instructors provide students to conduct the teaching and learning process. A washback effect refers to the flashback or the side effect of using handouts in students' learning.

The present study objective is to assess the washback effects of handouts on the teaching and learning process in higher education establishments of Ethiopia in general and in Adama University in particular.

In the present study, the research methods which were employed are the descriptive survey research method and the analytical research method with a special focus on a survey and a content analysis. A content analysis was used to analyse the extent to which the handouts being used in Adama University enhance self-learning, problem-solving skill, independent work, further reading and critical thinking. In short, through this method, it was checked whether the handouts are written in prose form, which does not call for asking and answering questions while reading, or gapped form, i.e. skeleton notes and worksheets that require the students to fill in via further reading/thinking thus removing passive elements in a situation where all the information is provided.

A survey was used to gather information from the sample instructors and students concerning the details of issues related with using handouts in the university. Moreover, a document analysis was employed to check whether or not there exists a guideline helpful for preparing handouts that enhance active learning in the university. 
The sources of data in the present study were instructors of Adama University, some students of the university, documents and some sample handouts. In short, both primary and secondary sources were used in the present study.

In the present research, out of the total of 632 teachers of Adama University, twenty five percent of them i.e. 158 teachers were selected as samples using simple random sampling and stratified sampling techniques. The simple random sampling technique was used to create a situation in which each teacher gets an equal chance to be included in the sample. On the other hand, the stratified sampling technique was employed to make the number of male and female teachers proportionally represented in the sample. Moreover, some handouts which are being prepared and used by Adama university teachers were taken from selected departments, and multistage sampling was used to select the chapters, topics, subtopics and the pages randomly.

In the present study, the data was gathered using four data collection instruments: a questionnaire, an interview, a content and document analysis. However, before using the tools for collecting the main data, a pilot study was conducted. The questionnaire was distributed among 20 randomly selected teachers. The reliability coefficients were computed using the internal consistency methods (Cronback, 1951, in Ferguson and Takane, 1989), and amendments were made accordingly. At last, the reliability of the overall instrument was found out to be $\alpha=0.78$.

According to Gay (1980), if a reliability coefficient is $\geq 0.50$, it can be accepted as a reliable instrument. So, based on this parameter, the items were found to have good grounds to be used in collecting the relevant data for the study.

To get additional data to that obtained from the teachers through a questionnaire, an interview was used as a data collection tool. To this end, a semi-structured interview was carried out to collect related information from some selected teachers and students.

A content analysis, on the other hand, was employed to check whether the staff of Adama University prepare handouts in activity-based ways that foster further reading or not. Furthermore, some documents were analysed to ascertain whether there exists a sound guideline for preparing handouts in the university.

To collect relevant data for the study, a questionnaire which comprises 17 items was designed. Moreover, to get additional data, semi-structured interview schedules were prepared. The items of the questionnaire and the interview were revised in such a way that they address the objectives of the study. Then, the questionnaire was distributed among 158 sample teachers. 140 teachers returned the questionnaire. To make the results of the study more valid and reliable, the interviews were carried out with randomly selected teachers and students. Furthermore, the obtained data was substantiated using a content and document analysis.

The data that was gathered using the four tools was analysed using both quantitative and qualitative approaches. The data that was collected through the close-ended items of the questionnaire and some items of the interviews were analysed quantitatively by applying a statistical method involving the chi-square statistic and the percentage.

Nevertheless, before applying the chi-square $\left(\mathrm{x}^{2}\right)$, the results obtained from 140 teachers through the questionnaire were sorted out and tallied. In scoring the responses of the subjects, the positively and negatively stated items were sorted out and the negatively 
stated items were reverse-scored and assigned scores and frequency numbers accordingly. Then, the chi-square was employed to determine the statistical significance of differences between the proportions of responses in the groups. The five-point scale was reduced into a dichotomous scale as the present study seeks to find out the washback effects of handouts on students' learning in Adama University. The value of the neutral option, namely, that of 'undecided' was liquidated proportionally to the disagree and agree sides (Babbie, 1995, as cited in Margo, 2008). The level of significance, in all the cases, was determined at $\mathrm{p}<0.05$. The data that was gathered using open-ended items of the questionnaire, some items of the interview, a content analysis and document analysis were not tabulated or computed.

\section{Results and discussion}

To check the extent to which the respondents use handouts in the teaching and learning process, a simple question was addressed in the questionnaire: How often do you use handouts in the courses you teach? In response to this question, out of the total 140 respondents, $21.43 \%$ said they use handouts very frequently in the courses they teach; $71.43 \%$ of the respondents reported that they use handouts frequently in the respective courses they teach; only $7.14 \%$ of the respondents said that they use handouts rarely. None of them said that they do not use handouts at all. This, in turn, reveals that almost all of the instructors use handouts at Adama University.

Table 1. Chi-square outline of the results of instructors' views on the use of handouts

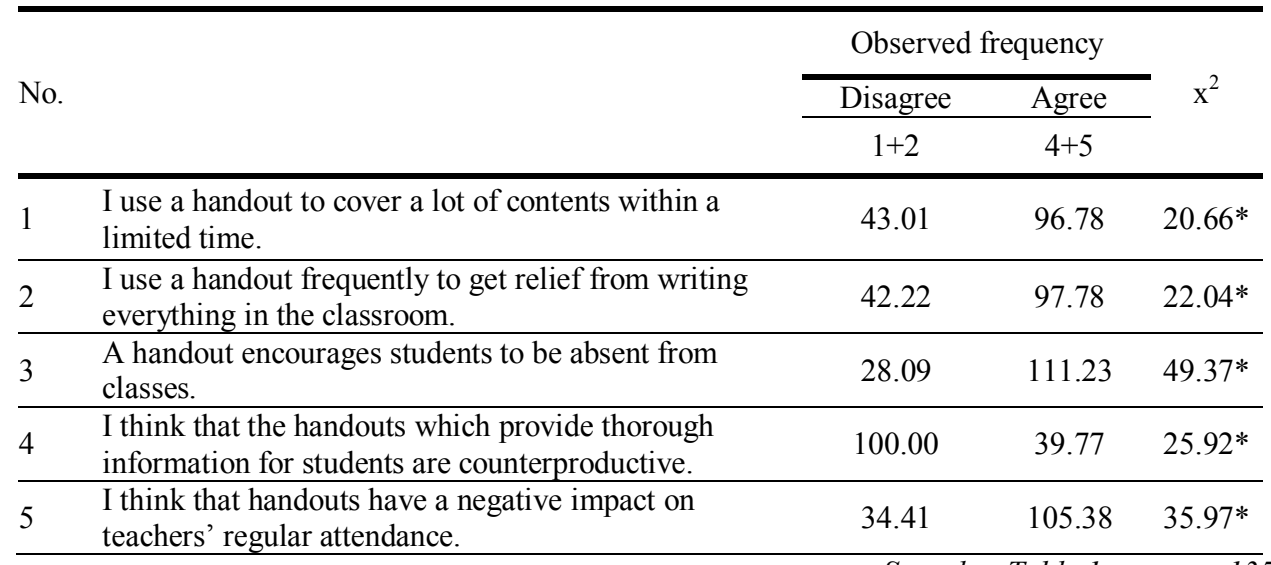

Sequel to Table 1 see on $p .135$. 
Sequel to Table 1.

\begin{tabular}{|c|c|c|c|c|}
\hline 6 & $\begin{array}{l}\text { Incomplete/compartmentalised handouts have the } \\
\text { tendency to make students voracious readers. }\end{array}$ & 102.20 & 38.46 & $29.02 *$ \\
\hline 7 & $\begin{array}{l}\text { I use alternatives such as internet, worksheets, } \\
\text { reference materials and the likes to handouts in the } \\
\text { courses I teach. }\end{array}$ & 95.34 & 44.18 & $18.69^{*}$ \\
\hline 8 & $\begin{array}{l}\text { Handouts minimise excessive works in lesson(s) } \\
\text { preparation and/or delivery; due to this, I usually use } \\
\text { them. }\end{array}$ & 30.23 & 109.29 & $44.64 *$ \\
\hline 9 & $\begin{array}{l}\text { Activity-based handouts have more advantages over } \\
\text { those prepared in prose form in relation to promoting } \\
\text { active learning. }\end{array}$ & 31.46 & 107.86 & $41.70^{*}$ \\
\hline & Overall items & 506.96 & 750.73 & $288.01 *$ \\
\hline $\begin{array}{l}{ }^{*} P \\
\text { N.B } \\
*=p \\
\text { df }\end{array}$ & & & & \\
\hline
\end{tabular}

As can be seen from Table 1, the calculated $\mathrm{x}^{2}$ value of all of the items is greater than the $x^{2}$ critical value $(1,0.05)$ which is 3.84 . The explanations given for each of the items is presented as follows.

In Table 1, the first item deals with whether Adama University instructors use handouts to cover a lot of contents within a limited time. Regarding this, the chi-square calculated value (20.66) is greater than the chi-square critical value $(1,0.05)$, which is 3.84 . As can be seen from Table 1, the magnitude and direction of the difference indicate that most of Adama University teachers use handouts to cover a lot contents within a short time.

Table 1 also shows the degree to which Adama University teachers use handouts frequently to get relief from writing everything in the classroom. Concerning this, the calculated $x^{2}$ value is 22.04 . As compared to the $x^{2}$ critical value $(1,0.05)$ which is 3.84 , it is by far greater which indicates the fact that most of the teachers in the university use handouts frequently to get relief from writing and/or doing everything in the classrooms.

Similarly, Table 1 depicts whether or not most of the teachers think that handouts encourage students to be absent from classes. In this case, the calculated $x^{2}$ value (49.37) is greater than the chi-square critical value $(1,0.05)=3.84$. Hence, most of the teachers in Adama University feel that handouts make students not attain classes regularly. The interview made with some selected informants also revealed that if teachers use handouts which have detailed descriptions of the course contents, students show little interest towards classroom attendance thinking that they can compensate the classroom lesson via independent readings.

Table 1 also illustrates whether most instructors feel that the handouts which provide thorough information for students are counterproductive. In this regard, the $x^{2}$ calculated value $(25.92)$ by far exceeds the $x^{2}$ critical value $(1,0.05)$ that is 3.84 . Therefore, the magnitude and direction of the difference show that the majority of the staff of Adama University is not aware of the negative consequences of preparing handouts explicitly. 
Moreover, Table 1 presents whether the teachers think that handouts have a negative impact on teachers' regular attendance. Concerning this, the $x^{2}$ calculated value (35.97) is greater than the $x^{2}$ table value $(1,0.05)$ that is 3.84 . Hence, the majority of the teachers feel that handouts make teachers to be absent from their regular teaching duties. In other words, the teachers think that if handouts are given to students, the students can read them, and the regular teaching responsibility can be compensated through students' independent reading.

Furthermore, Table 1 shows whether or not incomplete/compartmentalised handouts have the tendency to make students voracious readers. Accordingly, the calculated value of $\mathrm{x}^{2}$ is 29.02 . Compared to the $\mathrm{x}^{2}$ table value $(1,0.05)$ which is 3.84 , it is great. So, the magnitude and direction of the difference clearly show that the majority of teacher educators think that incomplete/compartmentalised handouts do not have the tendency to make students voracious readers.

Table 1 depicts whether the teachers use alternatives such as worksheets, reference materials and other materials except handouts in the respective courses. In this regard, the calculated value of $x^{2}$ is 18.69 . But, the magnitude and direction of the difference apparently show that the majority of teacher educators do not use alternatives, such as worksheets, reference materials and other materials in the respective courses they teach.

Table 1 also shows whether the teachers feel that handouts help them minimise excessive works in lesson(s) preparation and delivery. Concerning this, the calculated value of $x^{2}$ is 44.64. Compared to the critical value, the result is great and this implies that the majority of the teachers think that handouts help them to minimise their workload in both lessons' preparation and delivery.

Lastly, Table 1 shows whether the teachers feel that activity-based handouts have more advantages over those prepared in another form in relation to promoting active learning. Regarding this, the calculated value of $x^{2}$ is 41.70 . As compared to the critical value, it is great, and this implies that the teachers are aware of the advantages of using activity-oriented handouts instead of those prepared in another form to actively involve the learners.

In general, as it is shown in Table 1, regarding the overall use of handout and its flash back effects on the teaching and learning process, the calculated value of $x^{2}$ is 288.01 . Compared to the $\mathrm{x}^{2}$ critical value (at $1,0.05=3.84$ ), it is by far great, which indicates that all the items cited above, except a degree, are the key factors why Adama University teachers use handouts in the teaching and learning process.

As far as another question: Why do you think that university teachers frequently use handouts in the contemporary Ethiopian context of education? is concerned, the respondents reported that the main reasons are to cover a lot of portions within a very limited time, encourage students to read the handout before the actual class, minimise the workload and make the teaching and learning process as easy as possible. Besides, the respondents indicated more reasons: to overcome shortage of reference materials, make the students focus only on certain items as they are not interested in reading references, get time for running other personal businesses. Some teachers consider giving handouts a tradition Moreover, teachers lack the skill of how to create active learning environment, how to positively respond and treat students, how to address individual differences and how to ease and facilitate students' learning. 
To get additional information to the one gathered via the questionnaire, an interview was carried out with six randomly selected teachers, and most of them said that they usually use handouts to enrich what they teach, make students read during their spare time, cover excessive portions within limited time, help students develop reading habits and minimise the shortage of reference materials. One of the instructors said that:

Most instructors use handouts to conform to the longstanding teaching tradition in the universities of Ethiopia. Hence, they think that so far the students get something to read in relation to the course they learn. Nobody thinks about the side effects of the handouts that the students are using as resources. Moreover, since the instructors use handouts extensively, students consider handouts as sole sources of knowledge. As a result, they are totally dependent on the handouts given to them in the respective courses.

Another teacher responded to the interview as follows:

I use handouts mainly to cover some topics I should cover. I do not have the intention and skills to prepare activity-oriented handouts. Such preparation requires special training and the provision of adequate facilities.

Similarly, an interview was conducted with 10 randomly selected students, and almost of all them said that they use handouts to get ready-made information instead of searching for it in different books, get relief from writing lecture notes in the classes, easily get the focus of the subject teacher and minimise anxiety during examinations. During the interview, one of the students said that:

Handouts make university students get ready-made resources in relation to the courses they learn. So, they minimise worries as students can easily get the focus of the course under consideration. Hence, I really want our teachers to give us wellorganized handouts all the time. If I get handouts, I even do not care whether I attend classes or not.

Another student said:

Handouts are very important for university students as they help the students read in advance what the respective course teacher teaches. Besides, students can get additional time for entertainment and can even start reading only when exam dates approach.

Moreover, the content analysis on the selected handouts gathered from the teachers revealed that almost all of the handouts are prepared in an informative form. It does not call for further reading on the part of the students. In other words, the handouts lack pre-task activities, in-task activities and post-task activities that encourage further reading and critical thinking. In some cases, the handouts are directly copied from books and lack the inputs of the subject teachers. On the contrary, relatively, the handouts being used by social science teachers somehow consist of the inputs of the respective subject teachers. 
Furthermore, a document analysis was performed to check whether or not there exists a guideline or a model for preparing activity-based handout in the university. The results of the analysis showed that there is no any framework in the university that guide teachers for preparing handouts that enhance active learning as intended in the education and training policy of Ethiopia.

The majority of Adama University teachers make use of handouts in an informative format, though the education policy calls for an activity-based format. Moreover, there are no guidelines for preparing handouts in the university.

It was found that the majority of the instructors of the university lack awareness regarding the impacts of using handouts that provide thorough information.

The study revealed that the majority of teachers use handouts for the following reasons:

- to cover a lot of units within a very limited time;

- to enable students to read the handouts before the actual class;

- to minimise the workload;

- $\quad$ to make the teaching and learning process as easy as possible;

- to minimise a shortage of reference materials;

- to make the students focus only on certain items;

- to get time for running other personal businesses or to moonlight,

- to conform to the prevailing tradition;

- to backup students' poor capacity of taking notes;

- to maintain instructional sustainability as the handouts will remain with the learners;

- to maintain uniformity among the different groups of students;

- to satisfy students' high dependency on handouts.

It was also found that most of the Adama University teachers do not encourage students to use worksheets, references, module guides and other materials.

\section{Recommendations}

On the basis of the research findings, some recommendations are put forward.

1. To help Adama University teachers to prepare activity-based handouts, teachers' awareness should be raised. In this regard, training programmes which focus on how to transform the present isolated, teacher-centred and lecture note-bound mode of delivery into student-centred, interactive learning environment should be provided.

2. The teachers should be provided with guidelines for designing handouts which comprise pre-task, in-task and post-task activities will be included in the handout instead of using the conventional informative format.

3. To further enhance the students' learning, the university should make reference materials available, particularly provision of up-to-date references 
and access to e-media should be made available for both teachers and students.

\section{References:}

Ashcroft, K. (2004). The massification of higher education: A comparison of the UK experience and the emerging Ethiopian response. The Ethiopian Journal of Higher Education, 1(1), 21-40.

Bloom, D., Canning, D., \& Chan, K. (2006). Higher education and economic development in Africa. Harvard University: Human Development Sector Africa Region.

Cook, J., \& Cook, L. (1998). How technology enhances the quality of student-centered learning. Quality Progress, 31(7), 59-63.

Ellington, H., \& Race, P. (1993). Producing teaching materials (2 ${ }^{\text {nd }}$ ed.). New York: Nicholas.

Farrell, J. P. (1989). International lessons for school effectiveness: The view from the developing world. In M. Holmes, K. A. Leithwood, \& D. F. Musella (Eds.), Educational policy for effective schools (pp. 53-70). Toronto: Ontario Institute for Studies in Education.

Ferguson, G. A., \& Takane, Y. (1989). Statistical analysis in psychology and education $\left(6^{\text {th }}\right.$ ed.). New York: McGraw-Hill Book Company.

Fuller, B. (1986). Raising school quality in developing countries: What investments boost learning. Washington D.C.: The World Bank.

Gay, L. R. (1980). Educational evaluation and measurement. Columbus: Charles Publishing Company.

Kassaye, M. (2005). Ensuring the quality of Ethiopian higher education in the face of the challenges of the 21st century. The Ethiopian Journal of Higher Education, 2(2) 103131.

King, E. (1995). Educating girls and women: Investing in development. Washington, D.C: The World Bank.

King, E., \& Hill, M. A. (1993). Women's education in developing countries: Barriers, beliefs, and policies. Washington, D.C: The World Bank.

Lockheed, M. E., \& Verspoor, A. M. (1991). Improving primary education in developing countries. New York: Oxford University Press.

Marginson, S. (2008). Global, multiple and engaged: Has the 'idea of a university' changed in the era of the global knowledge economy? In Fifth International Workshop on Higher Education Reforms (pp. 1-24). East China: Normal University.

Margo, R(B). (2008). Retrospects and prospects of multicultural teacher education in the higher education institutions of Ethiopia: Adama University in focus. The Ethiopian Journal of Education, 28(2), 73-100.

Margo, R(B). (2006). Assessment of the contributions of Madda Walabu University to the Regional State of Oromiya. The Ethiopian Journal of Education, 3(1), 133-152. 
Margo, R(B). (2005). Trends and challenges of implementing active learning at Adama University. Proceeding of the October National Research Seminar. Adama: Adama University Printing Press.

Margo, R(B). (2002). Factors attributing to the mismatch between the intended and actually used teaching methods in the first cycle primary schools of Oromia. Addis Ababa: Addis Ababa University.

McLaren, P. (1989). Life in schools: An introduction to critical pedagogy in the foundations of education ( $2^{\text {nd }}$ ed.). New York: Longman.

Rajput, J. S. (1996). Universalisation of elementary education. New Delhi: Vikas Publishing House PVT Ltd.

Raudenbush, S. W., \& Willms, J. D. (1991). Schools, classrooms and pupils: International studies from a multilevel perspective. New York: Academic Press.

Semela, T. (2006). Higher education expansion the gender question in Ethiopia: A case study of women in a public university. The Ethiopian Journal of Higher Education, 3(1), 63-86.

Serbessa, D. D. (2006). Tension between traditional and modern teaching-learning approaches in Ethiopian primary school. Journal of International Cooperation in Education, 9(1), 123-140.

Tal, T. (2005). Implementing multiple assessment modes in an interdisciplinary environmental education course. Environmental Education and Research, 11(5), 575601.

Tessema, K. A. (2006). Contradictions, challenges, and chaos in Ethiopian teacher education. Journal for Critical Education Policy Studies, 4(1), 1-23.

Transitional Government of Ethiopia. (1994). New education and training policy. Addis Ababa: EMPDA.

Wallace, M. (1999). Guide on the side - why and how to avoid trashy handouts. Retrieved April 30, 1999, from http://www.llrx.com/columns/guide27.htm

Wondimu, H. (2004). Gender and regional disparities in opportunities to higher education in Ethiopia: Challenges for the promotion of social justice. The Ethiopian Journal of Higher Education, 1(2), 1-16.

\section{Acknowledgement:}

The researcher would like to thank Adama University for sponsoring this study via its research fund for the academic year 2008/2009.

\section{Correspondence:}

Robsan Margo Egne, Assistant Professor at Adama University, Ethiopia and a $\mathrm{PhD}$ student at University of Oslo, Faculty of Education, Institute for Educational Research, Sem Sælands vei 7, Helga Eng’s Building, 5th Floor, P.O.Box:1092 Blindern, NO-0317 Oslo, 
Norway. Tel: +4722844711; Fax: +4722854250. Email: robsanmargo@gmail.com; r.m.egne@ped.uio.no 